\title{
Psychological change in egogram for university student for years BANDO $\mathrm{H}^{{ }^{*}}$, YOKOYAMA $\mathrm{T}^{2}$
}

${ }^{1}$ Tokushima University and Medical Research, Tokushima, Japan

${ }^{2}$ Dept. of Advanced Technology and Science, Tokushima University, Tokushima, Japan

Corresponding Author: Hiroshi BANDO, MD, Ph.D., FACP

Address: Tokushima University /Medical Research, Nakashowa 1-61, Tokushima 770-o943, Japan; E-mail: pianomed@bronze.ocn.ne.jp

Received date: 17 September 2019; Accepted date: 1 October 2019; Published date: 7 October 2019

Citation: BANDO H, YOKOYAMA T. Psychological change in egogram for university student for years. Asp Biomed Clin Case Rep. 2019 Oct 07;2(2):48-51.

Copyright (C) 2019 BANDO H, YOKOYAMA T. This is an open-access article distributed under the Creative Commons Attribution License, which permits unrestricted use, distribution, and reproduction in any medium, provided the original work is properly cited.

\section{Abstract}

Background: Health problems concerning psychosomatic bio-psycho-social matters have been recently emphasized. Among them, the research for transactional analysis (TA) and egogram have been in focus. Authors have investigated egograms in various subjects including university students.

Case presentation: The case is a 23-year old male student. When he entered the university at 19 years, his egogram was good-hearted type (Type $\mathrm{Na}$ ). His current egogram is administrator type (AC inferior). Concerning egogram factors, the actual values were as follows: Critical Parent (CP) was 3 to 5, Nurturing Parent (NP) was 14 to 15 , Adult (A) was 5 to 15 , Free Child (FC) was 8 to 12 and Adapted Child (AC) was 12 to 5 .

Discussion: Elevated CP may be from understanding rules and organizational theories in society. Increased A is probably from learning the expertise of liberal arts, computers, mechanics and others in the university. When he was a freshman, he could not decide several matters by following other people from high AC level. Through his various experiences, he can judge adequately with achieving human growth. Consequently, AC seemed to be at the standard level. The current report will be expected to become useful reference for further research in the future.

\section{Keywords}

Bio-Psycho-Social; Psychosomatic Medicine; Personality; Egogram; Tokyo University Egogram (TEG)

\section{Introduction}

People are living in current society associated with various stresses. Therefore, in order to maintain our health, it is necessary to take appropriate measures not only for the body but also for the mind. In recent years, discussions on bio-psycho-social issues, selfefficacy, and self-affirmation have been recognized in psychology, psychosomatic medicine, psychiatry, education, and other fields [1]. These points would be related to the personality and egogram of each individual $[2,3]$.

In the actual practice of psychology, transactional analysis (TA) has been introduced by Eric Berne. He proposed a new trial method as one of the personality theory [4]. It was a psychotherapy to evaluate human adequate communication, using three ego states in each person, which are the fundamental PAC model with P (Parent), A (Adult) and C (Child). Consecutively, John Dusey developed the theory into application of 
five egos [5]. They are Critical Parent (CP), and Nurturing Parent (NP), Adult (A), Free Child (FC) and Adapted Child (AC) [5,6].

The study method of egogram has been implemented in Japan, and research has been conducted in a version by Tokyo University [7]. The authors have studied egograms in a variety of subjects including university students [8,9]. Especially, we have continuous relationship with them for years at university [8]. In this study, we will report a case where we examined the change in egogram at entering the university and entering graduate school.

\section{Case presentation}

The case is a 23-year old male student. He is $1^{\text {st }}$ grade of university graduate student at present. He received a psychological test of Tokyo University Egogram (TEG) recently. He received the same TEG test 4 years ago when he entered Tokushima University at the age of 19. These results of TEG were compared and investigated with the discussion of TEG after receiving university education for 4 years.

The results from both the TEG test were shown in (Fig-1). Regarding the psychological type, there was a change in the egogram type between 4 years ago and at present. The previous type was a good-hearted type (Type Na type), and the recent type was an administrator type (AC inferior type). Concerning the detail data of 5 factors, the actual values were as follows: CP was 3 to 5 , NP was 14 to 15 , A was 5 to 15 , FC was 8 to 12 and AC was 12 to 5 .

\section{Discussion}

As for the development of egogram research, TEG has been applied in Japan. The standard data were shown in thousands of subjects [7-11]. Authors and coresearchers showed the difference egogram pattern in

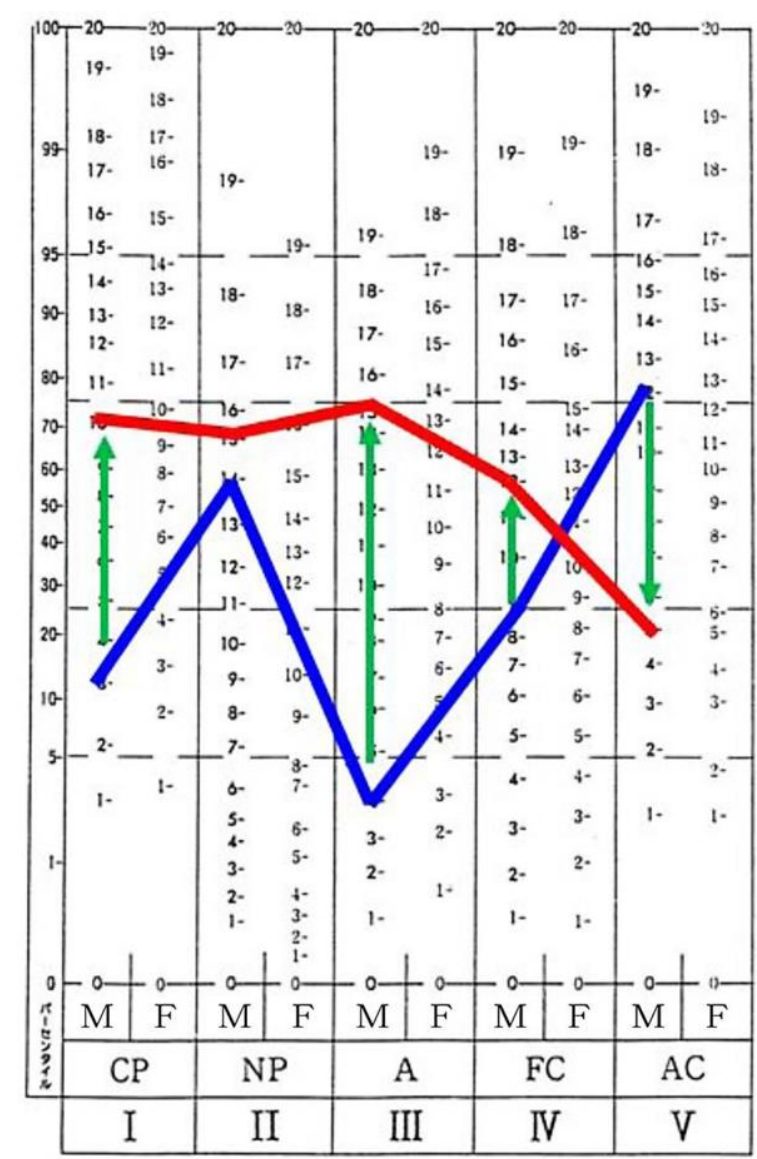

Fig-1: The changes in the egogram for 4 years.

Blue line: $1^{\text {st }}$ grade in university at 19 years old.

Red line: $1^{\text {st }}$ grade in postgraduate course at 23 years old.

Green arrow: direction of change 
subjects related with music learner, music teacher and control [12]. There is a research of egogram and personality concerning white-coat hypertension [13]. Further, the personality trait of hypertension seems to have low FC and high AC, suggesting that such personality may be involved in elevated blood pressure [14]. A recent study revealed that patients with atopic dermatitis showed characteristic egogram tendency and personality trait [15]. Thus, egogram research has been developed so far in various diseases and situations.

In the current study, the case showed the changes in egograms through four years of studying liberal arts and professional education. When the research of the egogram is conducted, three parts would be discussed respectively, which are parent, adult, and child [4].

Firstly, P factors include CP and NP. CP factor increased for 4 years. This may be involved in understanding rules and organizational theories. NP factor is almost the same, and it seems that there was no change in the kindness to others. Concerning NP factor, this factor has been a characteristic trait factor for the Japanese people [11]. In the egogram study for Japanese people, NP predominance pattern (kind mother or nursemaid type) has been frequently observed [11]. It shows the most common type at $15.8 \%$ among middle to elderly aged subjects [16]. In recent years, however, westernized ideas, behavior and lifestyle have been introduced in Japan. Then, the frequency of the adult dominant pattern (computer and intellectual type) has been increasing [8]. This tendency is the same in our research for university graduate students [10-17].

Secondly, Adult factor has increased in 4 years. Interpretation of this rise is thought to show the improved overall ability from university education for long [6]. In particular, the case has been a student majoring in engineering. Learning the expertise of computers and optics may have further increased the adult factor [8]. Through his various experiences for years, it has become possible to judge various matters correctly and adequately associated with achieving human growth.
Thirdly, Child factors showed the changes of FC and AC for 4 years. Elevated FC factor may present the psychological benefit of enjoying various matters [6]. On the other hand, the AC factor declined. When he entered the university 4 years ago, he did not feel confident and then he had to adjust to the actions and judgments of the people around him. This is speculated from an elevated AC level before [10].

After that, however, he has learned the liberal arts and specialized knowledge and information to a higher extent. He showed increased Adult recently, and then some confidence seems to be brought. Then, it is no longer necessary for him to follow other people around him, representing that $\mathrm{AC}$ factor has dropped to the standard level [9].

It is noteworthy that the AC factor and the balance with the other four factors are adequate. This is suitable for the qualities of leaders in various organizations [6]. In the medical practice, it is a preferable egogram that can be perfect for the nurse leader in the hospital ward. This egogram type seems to indicate a good administrator. One with such personality would have the ability to control both individuals and general management [17]. Thus, the postgraduate student seems to grow in the university education.

In this case, his own comment has been present. He has realized that he could grow during 4 years in the university. Specifically, he became to make reasonable decisions and to have responsibility for various jobs [8]. He has always thought deeply and he could improve and develop himself through his research life in the university [9]. He has been confident to be supported by egogram changes.

In summary, 23-year-old student showed the egogram changes with increased $\mathrm{CP}, \mathrm{A}, \mathrm{FC}$ and decreased AC factors. The results suggested the possibility of understanding organization rules and theories, judging various matters correctly and adequately, enjoying several situations and increasing his confidence for reasonable judgment in his daily life. We expect that current report would become useful reference for further research in the future. 


\section{References}

[1] Saitou T, Sugahara T, Kato C. A Study on the SelfAffirmation of University Student-Focusing on Classification by Personality. In 20187 th International Congress on Advanced Applied Informatics (IIAI-AAI). IEEE. 2018 Jul 8:506-11.

[2] Karumur RP, Nguyen TT, Konstan JA. Personality, User Preferences and Behavior in Recommender systems. Information Systems Frontiers. 2018 Dec 1;20(6):1241-65.

[3] Yoshiwara K, Tsuchiya H. Correlations among focusing attitudes, psychological competitive abilities and public self-consciousness in college athletes. Person-Centered \& Experiential Psychotherapies. 2019 Jan 2;18(1):85-97.

[4] Berne E. Transactional analysis. Ballantine Books; 1978.

[5] Dusay JM. Egograms: How I see you and you see me. Harper \& Row; 1977.

[6] Berne E. Transactional analysis in psychotherapy: A systematic individual and social psychiatry. Pickle Partners Publishing; 2016 Aug 9.

[7] Psychosomatic medicine department of Tokyo University. Egogram pattern new edition. Personality analysis. Kaneko publishing; 1995.

[8] Yokoyama T, Bando H. Study of Personality Traits for University Students by Egogram Analysis. Biomed J Sci\&Tech Res. 2018;9(3):001797.

[9] Bando H, Yokoyama T. Use of Egogram for Psychological Development of the Adolescence. Psychol Behav Sci Int J. 2018 Aug 10;9(4):1-3.

[10] Yokoyama T, Bando H. The Egogram Feature of Late Teenager in the Internet Generation. Clin Res Psychol. 2018;1(2):1-4.

[11] Kuboki T, Nomura S, Wada M, Akabayashi A, Nagataki M, Suematsu H, Yokoyama K, Araki S. Multidimensional assessment of mental state in occupational health care--combined application of three questionnaires: Tokyo University Egogram (TEG), Time Structuring Scale (TSS), and Profile of Mood States (POMS). Environ Res. 1993 May;61(2):285-98. [PMID: 8495670]

[12] Yoshioka A, Bando H, Yoshioka T. Effect of musical experience on optimization of egogram. Jap J Music Ther. 2004;4(2):191-97.

[13] Muneta S, Kobayashi T, Matsumoto I.
Personality characteristics of patients with "white coat" hypertension. Hypertens Res. 1997 Jun;20(2):99104. [PMID: 9220273]

[14] Kobashi G, Ohta K, Shido K, Hata A, Yamada H, Minakami H, Tamashiro H, Fujimoto S, Kondo K. The egogram is a potent, independent risk factor for hypertension in pregnancy. Semin Thromb Hemost. 2005 Jun;31(3):302-6. [PMID: 16052401]

[15] Cai L, Kaneko S, Morita E. Changes in salivary chromogranin A levels in adults with atopic dermatitis are correlated with changes in their condition. J Dermatol. 2018 May;45(5):554-59. [PMID: 29500830] [16] Shinoda T, Nakashita S, Hamada M, Hirono K, Ito M, Miyagi T, Namihira Y, Tokashiki T, Kashihara K, Nakashima K, Maeda T. Egogram characteristics in Japanese patients with Parkinson's disease. Neurology and Clinical Neuroscience. 2018 May;6(3):71-76.

[17] Bando H, Yokoyama T. Various Strokes for Development of Ego in the Transactional Analysis. M J psy. 2018;3(1):20. 